\title{
PATRIMONIO, VIÑEDO Y TURISMO: RECURSOS ESPECÍFICOS PARA LA INNOVACIÓN Y EL DESARROLLO TERRITORIAL DE CASTILLA-LA MANCHA
}

\author{
Julio José Plaza Tabasco \\ María del Carmen Cañizares Ruiz. \\ Ángel Raúl Ruiz Pulpón \\ Universidad de Castilla-La Mancha
}

\section{RESUMEN}

La revalorización del patrimonio cultural y la promoción del enoturismo constituyen factores indiscutibles de desarrollo en Castilla-La Mancha, puesto que, una vez integrados, desempeñan un papel clave en la consolidación de los procesos de gobernanza y en la creciente diversificación económica de las explotaciones agrarias. La implantación de estas estrategias está resultando bastante interesante en ciudades de tamaño medio como Alcázar de San Juan, ejemplo que permite descubrir la importancia de la construcción de capitales sociales territoriales para impulsar nuevos modelos productivos más sostenibles.

Palabras clave: viñedo, recursos específicos, patrimonio agrario, enoturismo, CastillaLa Mancha, Alcázar de San Juan.

\section{Heritage, vineyard and tourism: specific resources to innovate the territorial development of Castilla-La Mancha}

\section{ABSTRACT}

The valuation of the cultural heritage and the promotion of wine tourism are essential factors of territorial development in Castilla-La Mancha. When both are integrated, play a

Recibido: 2 de febrero de 2016

Devuelto para su revisión: 30 de junio de 2016

Aceptado: 28 de septiembre de 2016

Departamento de Geografía y Ordenación del Territorio. Facultad de Letras. Universidad de Castilla-La Mancha. Avda. Camilo José Cela s/n. 13017 CIUDAD REAL (España).E-mail: Julio.Plaza@uclm.es, MCarmen. Canizares@uclm.es,AngelRaul.Ruiz@uclm.es 
significant role in the consolidation of rural governance processes and increasing economic diversification of farms. The implementation of such strategies is becoming quite interesting in medium size cities such as Alcazar de San Juan, an example of the importance of territorial social capital is proved to promote new sustainable productive models.

Keywords: vineyard, specific resources, agrarian heritage, wine tourism, Castilla-La Mancha, Alcázar de San Juan.

\section{INTRODUCCIÓN: NUEVAS FORMAS DE DESARROLLO Y DE DIVERSIFI- CACIÓN ECONÓMICA EN LOS ESPACIOS RURALES}

Los espacios rurales han vivido en las últimas décadas una intensa reestructuración social y económica favorecida por la consolidación de los procesos de globalización, a los que ahora se suman los efectos de la actual crisis global con repercusiones aún no suficientemente evaluadas en los gobiernos de los territorios y en su capital social. La superación de la crisis exige un nuevo esfuerzo en innovación y en aprovechar con mayor intensidad las ventajas competitivas y diferenciadoras de cada territorio, que se puede plasmar en un nuevo paradigma sobre el desarrollo rural (Torre y Wallet, 2015).

La globalización, entendida como el proceso económico, tecnológico, social y cultural a escala planetaria basado en la creciente comunicación e interdependencia entre los países (López Trigal, 2015: 300), ha derivado hacia una mayor apertura de los mercados y una evidente debilidad de los Estados-Nación para planificar y desarrollar sus políticas agrarias de forma independiente (Segrelles, 2001). Otras consecuencias sobre los espacios rurales han sido la intensificación productiva de las explotaciones para ser más competitivas y el control de los circuitos de distribución de alimentos básicos por parte de grandes corporaciones transnacionales. Frente a este tipo de tendencias con importantes implicaciones ambientales y sociales, han surgido soluciones basadas en dinámicas de innovación y desarrollo territorial integrado a escala local o subregional que aprovechan los valores naturales, paisajísticos y culturales para conformar estrategias de diferenciación, conscientes de la necesidad de integrarse en unos mercados cada vez más exigentes y que demandan una mayor diferenciación de los productos. En este tipo de soluciones las explotaciones agrarias están reorientando gradualmente sus economías, incorporando nuevos criterios relacionados con la extensificación, la diversificación, la calidad y la conservación del medio ambiente y del paisaje. Del mismo modo sucede con las administraciones públicas y el conjunto de la sociedad civil, que se han convertido en dinamizadoras del tejido social y productivo a través de estrategias de innovación que buscan mejorar la calidad de los productos agrícolas y poner en valor los recursos patrimoniales que generan identidad y cohesión territorial.

De esta forma, el patrimonio ha adquirido un protagonismo destacado en la economía de los espacios rurales, en particular el vinculado con la agricultura, pues encarna una forma singular de trabajar el territorio, cuyo resultado es un rico legado que ahora también es revalorizado por su riqueza emotiva, identitaria, ambiental y recreativa (Rosenberg y Walsh, 1997: 296; Ruíz Urrestarazu, 2001; Silva, 2009: 135). Se impone 
una nueva concepción del objeto patrimonial que no abarca únicamente el edificio con valor histórico-artístico, sino también los propios paisajes, los sitios históricos, los emplazamientos y entornos construidos, la biodiversidad, los objetos diversos, las tradiciones pasadas y presentes o determinadas experiencias vitales (ICOMOS, 1999).

Estos giros en las estrategias de la producción agraria, en la valorización del patrimonio como recurso territorial, y en la dinamización de la sociedad local se pueden explicar observando el cambio producido en los gobiernos donde se está consolidando una nueva gobernanza rural (Woods, 2005:160). Las nuevas formas de organización territorial repercuten directamente en los tejidos sociales y económicos de las poblaciones, en sus administraciones, ciudadanos, instituciones y empresas, incluyendo en estas a las explotaciones agrarias, las agroindustrias y las empresas turísticas. Concretamente en Europa se ha defendido la conformación de espacios policéntricos alternativos al crecimiento metropolitano para reforzar las conexiones urbano-rurales siguiendo las orientaciones de documentos como la Estrategia Territorial Europea o las Agendas Territoriales (Pillet et al., 2014). Las ciudades de tamaño medio han incorporado la innovación territorial como una forma creativa de superar las debilidades estructurales y conseguir mayor integración regional, desarrollando procesos de aprendizaje individual y colectivo y empleando los recursos específicos de forma sistémica. Este proceso ha tenido como resultado lo que podríamos denominar "territorios innovadores" o "proyectos territoriales" (Méndez, 2003: 184; Méndez et al., 2006: 388), donde se integran aspectos económicos, de bienestar social, ambientales, de innovación y aprendizaje y participación e interacción social. Como resultado se conforman partenariados a distintos niveles y orientaciones temáticas, que se han apoyado en la innovación y en el capital social territorial para impulsar proyectos orientados a ofrecer una mejora en la calidad de vida de sus ciudadanos, al tiempo que una mayor capacidad de atracción a nivel global desde lo local.

Al impacto de la "glocalización" sobre la nueva división internacional del trabajo y las formas de gobernabilidad (Alonso y Conde, 1996; Pillet, 2008), se suman los efectos de la crisis global, primero de carácter financiero ligada al sector de la construcción y luego más vinculada con las políticas de ajuste de carácter neoliberal (Méndez et al., 2015: 17). En relación con los efectos de la crisis en el mundo rural, se pueden distinguir varios aspectos, entre los que destacamos dos relacionados con la temática que nos ocupa: por una parte la destrucción de capital social que se traduce en proyectos públicos y privados cancelados o inacabados, y por otra las dificultades para el surgimiento y consolidación de nuevas fórmulas de organización. En ambos casos se requieren estrategias de innovación social y económica que fomenten la cohesión alrededor de los recursos específicos de carácter territorial como son el patrimonio y el turismo asociado al cultivo del viñedo y a la producción de vinos (enoturismo).

Estos procesos son visibles en regiones periféricas y de baja densidad como Castilla-La Mancha (España), donde la agricultura y la construcción representan el 7,46\% y el 6,7\% del PIB regional frente al 2,49\% y el 5,56\% de España, respectivamente (INE, 2014). El fuerte peso de estos dos sectores económicos, destacando aquí el monocultivo de la vid en el sector primario, obligan al conjunto de actores regionales a una reorientación del modelo productivo mediante la transición agrícola, la valoración del patrimonio o la 
dinamización de una nueva gobernanza rural. A los problemas socioeconómicos se suma el abordaje de determinados problemas ambientales debidos a la sobreexplotación de los recursos hídricos (Ruíz Pulpón, 2012; Aragón et al., 2015). Las estrategias orientadas a resolver esta situación dotarán al territorio de una mayor capacidad de organización para combatir los efectos negativos o destructores de la crisis global.

Abordamos aquí de manera concreta la incorporación del patrimonio cultural (agrario) y del enoturismo a los procesos de innovación y de construcción de capital social, bajo la hipótesis de que son recursos específicos fundamentales para reforzar la gobernanza territorial y el tejido de una de las principales redes de cooperación en el mundo rural, que es la de la actividad agraria. Todo ello desde una óptica revisada de lo que hoy se considera patrimonio cultural, pues ya no hace referencia al monumento con valor histórico-artístico sino que, bajo un enfoque más dinámico, no depende de los objetos o bienes sino de los valores que la sociedad en general les atribuyen en cada momento de la historia y que determinan qué bienes son los que hay que proteger y conservar para la posteridad ${ }^{1}$. Más aún, en un contexto de incertidumbre y limitación de recursos, en el que las administraciones públicas han visto condicionadas sus actividades de promoción del enoturismo y de recuperación del patrimonio.

Para responder a estas cuestiones, en los primeros apartados presentamos los marcos conceptuales sobre el comportamiento de las explotaciones agrarias dedicadas al viñedo; la valorización del patrimonio agrario, y las políticas de desarrollo local como formas de dinamización de proyectos territoriales. A continuación analizamos las estrategias que se han impulsado en Castilla-La Mancha en relación con el sector vitivinícola, el patrimonio, y la promoción de una nueva gobernanza rural. En la segunda parte expondremos algunas de las iniciativas desarrolladas en ciudades de tamaño medio, concretamente en la ciudad de Alcázar de San Juan (31.269 habitantes en 2015), donde la cooperación multinivel entre actores públicos y privados ha generado un modelo de "buena gobernanza" (Michelini, 2010: 199), que incluye acciones en materia de patrimonio y de turismo.

Para la elaboración de este artículo nuestra metodología ha partido del estudio de las fuentes bibliográficas y estadísticas relacionadas con el objeto de estudio, y para la caracterización del caso de estudio se han empleado fuentes hemerográficas, entrevistas y trabajo de campo. Los primeros resultados apuntan a que en Castilla-La Mancha, la cultura del vino está aún condicionada por la sobreproducción, y que las inversiones en proyectos turísticos sólo parecen interesar a pequeños agricultores-elaboradores de vino, mientras que las administraciones locales defienden esta actividad como una vía para preservar su patrimonio cultural y proyectar su marca territorial en el desarrollo local. Los grandes productores, bodegas privadas y cooperativas, priorizan ante todo la calidad y el precio como únicas fórmulas de competir en los mercados, y no manifiestan una actitud suficientemente receptiva a las nuevas demandas de carácter cultural y/o turístico.

1 http://www.iaph.es/web/canales/patrimonio-cultural/ 


\section{LAS ESTRATEGIAS PARA EL DESARROLLO TERRITORIAL EN TORNO AL SECTOR VITIVINÍCOLA DE CASTILLA-LA MANCHA (ESPAÑA)}

Castilla-La Mancha alberga 2.059.191 habitantes según los últimos datos ofrecidos por el Instituto Nacional de Estadística en España para 2015. De un total de 919 núcleos de población, solo 40 superan el umbral de los 10.000 habitantes, es decir, son urbanos, y de ellos solo 14 tienen más de 25.000 , en los que vive aproximadamente el $42 \%$ de la población total de la región (Figura 1). Los restantes, 879 municipios no urbanos, albergan al otro $58 \%$ de la población regional, existiendo 733 con menos de 2.000 habitantes, de ahí que, tradicionalmente, haya sido calificada como una región con un importante componente de ruralidad asociado a la agricultura y, de forma concreta, con los cultivos de la trilogía mediterránea: cereal, vid y olivo. La industrialización ha sido lenta y tardía, y predomina un sector terciario vinculado al comercio, los servicios públicos y el turismo.

\section{Figura 1 \\ LOCALIZACIÓN DE CASTILLA-LA MANCHA EN EUROPA Y DISTRIBUCIÓN DE SUS PRINCIPALES CIUDADES}

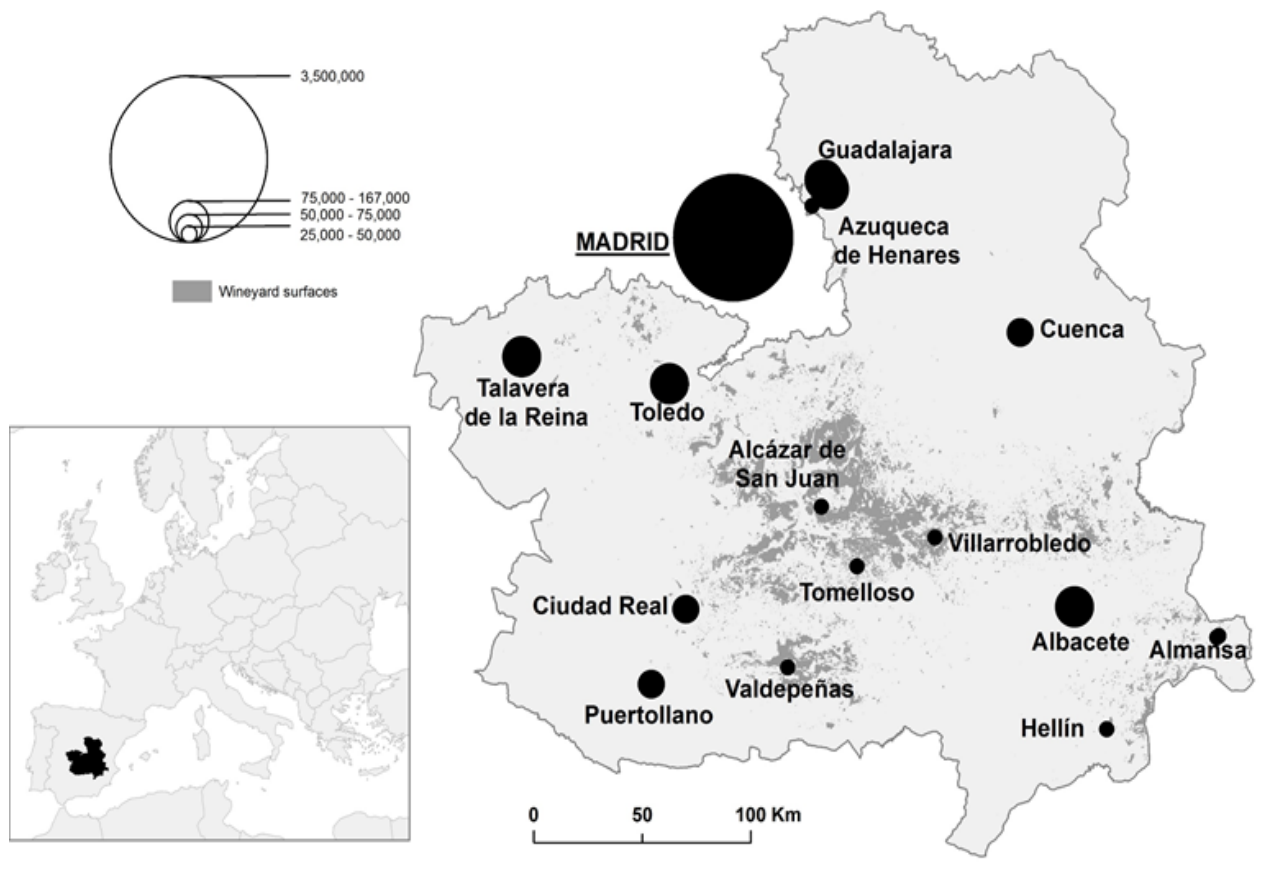

Fuente: INE, Padrón de Población 2014. Elaboración propia.

Con casi $80.000 \mathrm{~km}^{2}$ es la región que más superficie dedica al cultivo del viñedo en Europa. Según el Ministerio de Agricultura, esta Comunidad Autónoma presentaba 437.072 hectáreas dedicadas a este aprovechamiento en 2012, lo que suponía el 46,1\% de 
las superficies de viñedo nacional, el $13 \%$ de la Unión Europea y el 6\% de la superficie cultivada a nivel mundial. La producción de vino en Castilla-La Mancha ronda los 15,2 millones de hectólitros, un 48,9\% del total español, aunque con importantes fluctuaciones anuales, debido fundamentalmente a la climatología; por ejemplo, en la cosecha del año 2013 se alcanzó la cifra record de 31,2 millones de hectólitros (alrededor del 75\% de la producción de Francia ese mismo año). Las mayores superficies de viñedo se concentran en la zona central de la región, en la comarca de La Mancha y también, en la zona de Valdepeñas.

A pesar de la retirada de viñedo de secano para controlar la sobreproducción, las cosechas se mantienen en los últimos años debido al incremento del viñedo regado, lo que conduce a continuos vaivenes en el precio final de los vinos y a una fuerte dependencia de las exportaciones como producto genérico. Para resolver esta situación y posicionarse adecuadamente en los mercados frente a la competencia de otras regiones vitivinícolas emergentes a nivel mundial, es preciso introducir algunas lógicas de carácter postproductivista, basadas tanto en una mayor extensificación del cultivo y mejora de la calidad, además de la diversificación de la economía regional con nuevas actividades como el enoturismo o la puesta en valor del patrimonio.

\subsection{Las estrategias relacionadas con el postproductivismo agrario}

La pluriactividad en las explotaciones agrarias y la revalorización del patrimonio cultural son estrategias de innovación que ayudan a contener la incertidumbre que vive el sector agrario en el momento actual, aportando un discurso de coherencia e identidad frente a la producción vitivinícola estandarizada. Ambas fórmulas se fomentan dentro del postproductivismo agrario, concepto que designa el nuevo marco de relaciones entre las políticas agrarias y ambientales que surgieron a finales del siglo XX, junto a las políticas de extensificación de la producción y de defensa de la calidad y la salubridad de las producciones alimentarias, en respuesta a la preocupación de los consumidores (Ilbery y Bowler, 1998; Armesto, 2005; Mather et al., 2006).

A pesar de que algunas de estas cuestiones se revelen necesarias en el contexto del cumplimiento de los compromisos de la Política Agraria Común a partir de 1992, o que el postproductivismo haya sido cuestionado por su aparente inexistencia o por su pérdida de vigencia por otras narrativas sobre la transición agraria en Europa como el neo-productivismo o el no-productivismo (Evans et al., 2001; Wilson and Burton, 2015), no podemos olvidar que se trata de una respuesta lógica a las inquietudes de la sociedad postindustrial actual, que muestra un creciente interés por la conservación ambiental y patrimonial. En este sentido, el postproductivismo interpreta el medio rural como un lugar donde se integran valores ambientales, paisajísticos y culturales (Rosenberg y Walsh, 1997), reflejando una historia cultural y natural específica que configura sentimientos emotivos y estéticos en torno a un determinado tipo de organización territorial, de paisajes y de tradiciones propias (Ruiz Urrestarazu, 2001).

La influencia del postproductivismo se percibe de forma muy evidente en el viñedo a través de su incuestionable trasfondo histórico y cultural en muchas regiones de la Europa Mediterránea, y mediante los esfuerzos realizados en innovación y en calidad de las pro- 
ducciones. Como representa la Figura 2, esta influencia se manifiesta en cuatro procesos adaptativos: la extensificación de la producción, que rebaja o elimina el consumo de agua, de fertilizantes y productos fitosanitarios; la promoción de indicaciones geográficas que regulan la calidad y procedencia de los vinos; la diversificación de las explotaciones principalmente a través del enoturismo; y la asociación del producto vitivinícola a los valores escénicos, ambientales y culturales de los paisajes.

\section{Figura 2}

\section{POSTPRODUCTIVISMO Y SU INFLUENCIA EN EL SECTOR VITIVINÍCOLA}

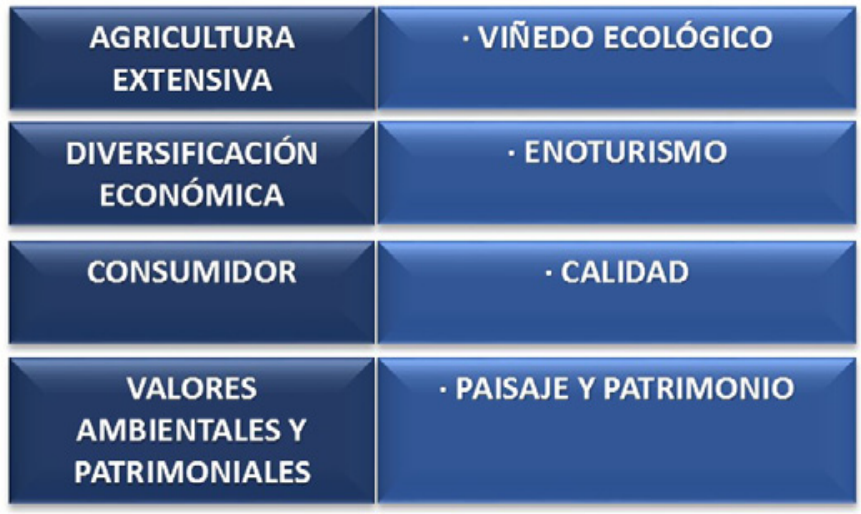

Fuente: elaboración propia.

En el caso de Castilla-La Mancha, la extensificación de la producción ha supuesto un incremento de la producción de vino ecológico, que ha pasado de unas escasas 1.487 hectáreas en 2001, a 47.630 en 2011, lo que supone el $60 \%$ de la viticultura ecológica en España (Ruiz Pulpón, 2013), aunque el notorio ascenso estaría más vinculado a la necesidad de rentabilizar las explotaciones de viñedo de secano mediante subsidios, que a una respuesta de mayor concienciación ambiental por parte del agricultor, en la línea de los discursos críticos con el postproductivismo.

En relación con la calidad, el tejido social y profesional han llevado a cabo un proceso de modernización centrado en la multiplicación de las actividades dedicadas a la crianza, el embotellado y la exportación en los últimos años, fruto de la reorientación productiva surgida al amparo de las últimas Organizaciones Comunes del Mercado Vitivinícola, que velaban por la adecuación de la producción vitivinícola al comportamiento de los mercados. Tampoco habría que olvidar, en este sentido, el apoyo de las administraciones, en concreto, del Gobierno Regional de Castilla-La Mancha que se apresuró al reconocimiento de Denominaciones de Origen de Calidad para vinos producidos en determinados Pagos Vitícolas, protegiendo aquellos vinos elaborados en terroirs, donde hay una relación completa y específica entre el territorio y el producto elaborado (Ramírez y Del Canto, 2008). Los criterios empleados para el reconocimiento administrativo de esta clase de vinos manifiestan, por sí mismos, tendencias postproductivistas, pues incluyen los condi- 
cionantes geográficos que definen la personalidad de los vinos, los métodos y las técnicas empleadas en el proceso de elaboración, la preocupación por fomentar prácticas agronómicas sostenibles, y la puesta en marcha de nuevas actividades que integran la revalorización patrimonial, la calidad del producto, y la difusión de actividades turísticas como ejes para perfilar estrategias innovadoras de desarrollo territorial (Ruiz Pulpón, 2013; Cañizares y Ruiz Pulpón, 2014a).

El proceso de adaptación de estrategias postproductivistas es consecuencia de un proceso de aprendizaje que depende de la actitud de las explotaciones agrarias hacia la adopción de estrategias de multifuncionalidad y de comportamientos productivos o no productivos (Wilson y Burton, 2015), frente a la preocupación dominante por la comercialización. Ello obliga a desarrollar estrategias de cooperación e innovación a distintas escalas, y con múltiples agentes territoriales en la valorización del patrimonio agrario y específicamente el asociado con el cultivo del viñedo, entre los que sobresalen las administraciones públicas locales.

\subsection{La valorización del patrimonio agrario vitivinícola}

El patrimonio agrario vitivinícola se ha visto tradicionalmente infravalorado en los modelos de producción estandarizada. Como reacción a esta práctica, en 2012 se elaboró la Carta de Baeza sobre Patrimonio Agrario que reconoce el valor de los bienes naturales y culturales, materiales e inmateriales, generados o aprovechados por la actividad agraria a lo largo de la historia. Además, el Patrimonio Agrario debe asumir como propios aquellos valores y significados más elevados y trascendentes que la agricultura, la ganadería y la silvicultura representan para las personas: su aportación a la alimentación; su relación armónica con el territorio, manifestada en un aprovechamiento sostenible y dinámico de los recursos naturales; su identidad esencial como parte de la relación cultura-naturaleza; y su imprescindible contribución a la diversidad biológica (manifestada en la heterogeneidad genética de las variedades locales y razas autóctonas) y cultural (asociada a las innumerables formas de manejo existentes en el mundo). Se reclama, entonces, el reconocimiento del valor agrario como valor general para la identificación de este tipo de bienes y, de forma específica, los valores agronómico, económico, social, ecológico, histórico, paisajístico y técnico (Castillo, 2013).

La consideración del patrimonio agrario como un nuevo tipo de bien cultural que hay que proteger y ordenar nos lleva, pues, a la valoración e integración de sus elementos (materiales e inmateriales) convertidos en recursos en las estrategias de desarrollo como está comenzando a suceder en Castilla-La Mancha. La Carta de Baeza ofrece un procedimiento de ordenación y clasificación que, con algunas matizaciones, puede ser aplicable a cualquier paisaje agrario regional y particularmente a los de viñedos (Cañizares y Ruíz Pulpón, 2014b: 310 y ss.) (Cuadro 1).

Hacemos referencia inicialmente, a los elementos del patrimonio material o tangible, distinguiendo en primer lugar los bienes muebles relativos a los útiles, aperos y herramientas usados en la labranza de la vid y en el almacenamiento y producción de vinos como las prensas, tinajas, atrojes, pisadoras y estrujadoras; los elementos relacionados con el transporte como los diferentes tipos de carros y animales de tiro; los documentos 
y objetos bibliográficos que se concretan en la relación entre el viñedo y la literatura, destacando la literatura de viajes (en Castilla-La Mancha con autores como Antonio Ponz o el Barón de Davalier), así como obras pictóricas que reflejan el paisaje de la viña (de artistas locales como Antonio López Torres, Antonio López Villaseñor y Gregorio Prieto). También relevantes son los bienes inmuebles, entre los que distinguimos los singulares (edificaciones) y los de conjunto y lineales (paisajes). Los singulares se identifican con construcciones de cierta originalidad, tales como bombos, quinterías, chozos, casas de labranza, corralizas, palomares, norias, majadas, fuentes, pozos y albercas, etc., así como también las construcciones asociadas con la transformación de la producción, en especial bodegas y alcoholeras, representativas tanto de procesos artesanales en forma de bodegas familiares unidas frecuentemente a las viviendas, como de la producción a gran escala en caso de las bodegas industriales (Cañizares, 2005: 81), algunas de las cuales se han convertido en museos como el Museo del Vino de Valdepeñas (Ciudad Real), antigua bodega de Leocadio Morales. Respecto a los bienes inmuebles de conjunto y lineales destaca, sobre todo, el propio "paisaje del vino" donde apreciamos la convivencia actual del viñedo tradicional (Figura 3), cuyo valor patrimonial es indiscutible, con el viñedo en espaldera fruto de la modernización del cultivo. A ello añadiríamos los asentamientos de población, en este caso asociados a un poblamiento concentrado, y los caminos y vías pecuarias, muchos de ellos de origen medieval.

\section{Cuadro 1}

\section{PRINCIPALES ELEMENTOS DEL PATRIMONIO AGRARIO VITIVINÍCOLA}

\begin{tabular}{|c|c|c|}
\hline \multirow{3}{*}{$\begin{array}{l}\text { Patrimonio } \\
\text { Material o } \\
\text { Tangible }\end{array}$} & \multirow{3}{*}{ Bienes muebles } & $\begin{array}{l}\text { Útiles, aperos y herramientas para la labranza de la vid } \\
\text { Útiles para la producción de vinos y el almacenamiento } \\
\text { Elementos relacionados con el transporte }\end{array}$ \\
\hline & & Documentos y objetos bibliográficos \\
\hline & & Obras artísticas (pintura,...) \\
\hline & $\begin{array}{l}\text { Bienes inmuebles } \\
\text { singulares }\end{array}$ & Construcciones (arquitectura tradicional) \\
\hline & $\begin{array}{l}\text { Bienes inmuebles de } \\
\text { conjunto o lineales }\end{array}$ & $\begin{array}{l}\text { Paisaje del vino (cultivos) } \\
\text { Asentamientos de población } \\
\text { Red caminera }\end{array}$ \\
\hline \multirow{4}{*}{$\begin{array}{l}\text { Patrimonio } \\
\text { Inmaterial o } \\
\text { Intangible }\end{array}$} & & $\begin{array}{l}\text { Lenguaje (términos) } \\
\text { Refranero popular }\end{array}$ \\
\hline & & Creencias, rituales y actos festivos \\
\hline & & $\begin{array}{l}\text { Saberes, los oficios y las tradiciones propias de la } \\
\text { labranza de la vid. Artesanía }\end{array}$ \\
\hline & & Gastronomía típica \\
\hline \multirow{2}{*}{$\begin{array}{l}\text { Patrimonio } \\
\text { natural y } \\
\text { genético }\end{array}$} & \multirow{2}{*}{$\begin{array}{l}\text { Características físicas } \\
\text { Tipos de uva }\end{array}$} & Relieve, clima, suelos, etc. \\
\hline & & Propias de cada territorio (autóctonas) y/o importadas \\
\hline
\end{tabular}

Fuente: Carta de Baeza (2012) y elaboración propia. 


\section{Figura 3 \\ PAISAJE DE VIÑEDO TRADICIONAL EN LA ZONA DE VALPEDEÑAS (CIUDAD REAL, CASTILLA-LA MANCHA)}

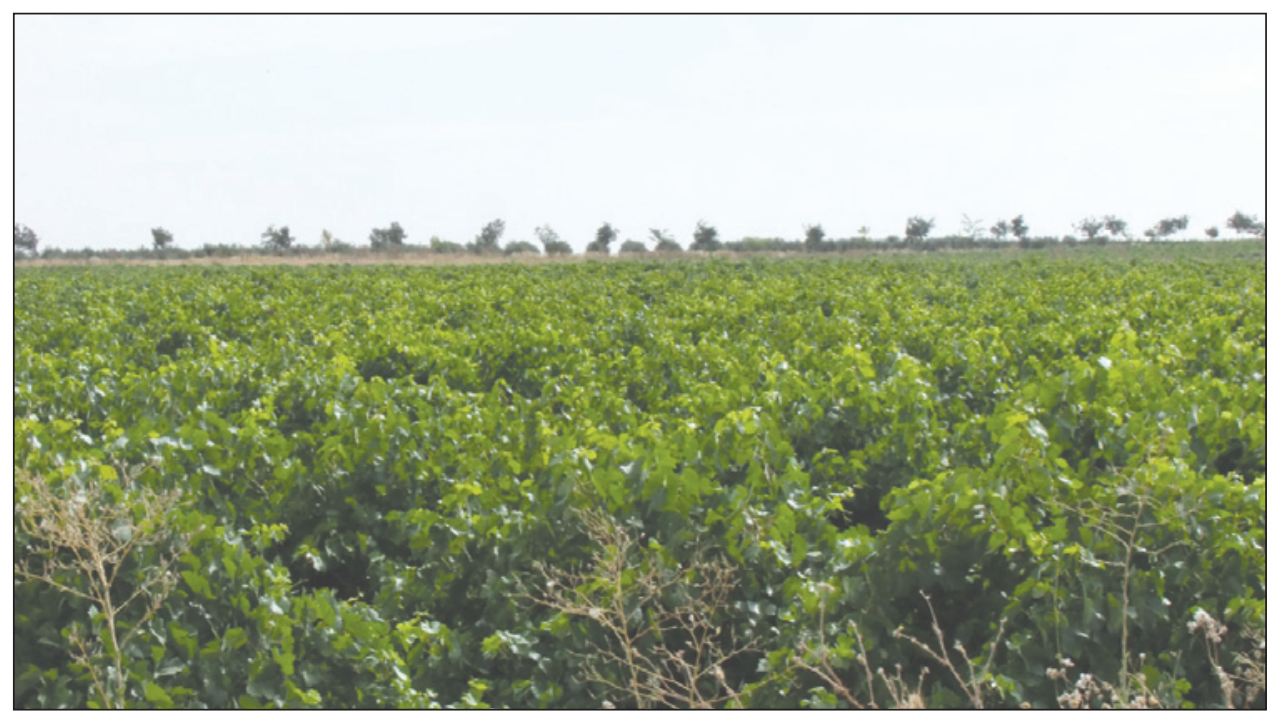

Fuente: M. Carmen Cañizares (2013).

En relación con el patrimonio inmaterial o intangible, resaltamos, en primer lugar, el lenguaje con términos específicos asociados a la cultura del vino como, por ejemplo, "majano" (cúmulo de piedras que señalan la separación de parcelas); sin olvidar el refranero popular: "Las viñas en manos extrañas: grama, broza y telarañas". En segundo lugar, identificamos creencias, rituales y actos festivos relacionados con la viticultura, principalmente las fiestas locales asociadas a la religión, como la Romería de la Virgen de las Viñas en Tomelloso, y al vino, como la Fiesta de la Vendimia y de la Poesía de Valdepeñas que se organiza desde 1953. En tercer lugar, descubrimos los saberes, los oficios y las tradiciones propias de la labranza de la vid, sobresaliendo por encima de todas las tareas de vendimia y sus rituales; la artesanía de forja y cuchillería para la elaboración de utensilios y herramientas, el trabajo del mimbre y el esparto para la confección de cestos, esteras y capachos, y el trabajo de la piel, principalmente, para la confección de botas de vino. Muy importante, también, es la gastronomía típica en la que el vino tiene la función de acompañamiento para platos como las gachas, migas, pisto manchego, pipirrana, duelos y quebrantos, caldereta o tiznao, entre otros. Vinos que son blancos, en su gran mayoría, y tintos bajo diferentes tipologías: jóvenes, de crianza, reserva y gran reserva. Por último, no debemos olvidar que el potencial natural está basado en unas características físicas peculiares, que en este caso se definen por el predominio de las llanuras y planicies, por una climatología extrema (continentalidad), y por suelos arcillosos aptos para el cultivo de la vid; que se completaría, desde el punto de vista genético, con una considerable diversidad de tipos de uva (airén, cencibel,...). 
Todos estos elementos descubren el enorme potencial del patrimonio del cultivo del viñedo castellano-manchego al contemplarlo como recurso, en su totalidad y en cada uno de los elementos citados, que debe ser protegido y es capaz de sustentar un producto turístico de calidad que comienza a tener una cierta relevancia en sus múltiples tipologías (enoturismo, ecoturismo, turismo cultural). Como en otros lugares de Europa, la revalorización del patrimonio agrario es, pues, un indicador más de cómo los valores recreativos, culturales y escénicos de los medios rurales han sido reinterpretados en la actualidad, idealizándolos en clave de autenticidad (Short, 2005) y ello conduce a la posibilidad de que algunos paisajes de viñedo puedan ser reconocidos como Bienes de Interés Cultural como se ha analizado para el caso de la D.O. Valdepeñas (Cañizares y Ruiz Pulpón, 2016: 551 y ss.).

\subsection{El enoturismo como estrategia territorial}

La puesta en valor de algunos de los recursos citados ha facilitado el desarrollo en esta región, como en otras, de una modalidad de turismo específica, el turismo del vino o enoturismo, también denominado turismo enológico, al interrelacionar las nuevas demandas de turismo cultural y las estrategias de promoción y de diversificación económica de las bodegas (Getz y Brown, 2006: 147; Pedraja y Marzo, 2014), e incluso enogastronómico, siguiendo el Plan Nacional e Integral del Turismo (2012-2015) en España (Pillet, 2015b: 192). En este caso, utilizando el concepto de enoturismo queremos resaltar que cuenta con un evidente valor identitario porque el vino se considera un bien patrimonial, generando nuevos yacimientos de empleo y proponiendo nuevas perspectivas socioeconómicas, además de formar parte del atractivo de muchas comarcas españolas en relación con el patrimonio territorial (Pillet, 2012).

En el ámbito sociocultural se convierte en un nuevo recurso educativo para la sensibilización con aspectos asociados al medio ambiente, el saber hacer, a la tradición y a los valores del paisaje (Martínez, 2014: 503-506). Su intensificación en los últimos años ha estado vinculada con la mejora de la calidad de los vinos, en función de las diferentes denominaciones de origen, los paisajes de cultivo de viñedo y sus construcciones singulares (bodegas, principalmente), así como la gastronomía, es decir con elementos culturales e históricos que son claro "reflejo de la identidad propia de una zona geográfica" (Rodríguez et al., 2010: 218) que ofrece un complemento dentro de un turismo de calidad (Pillet, 2011: 734). Por su parte, en el ámbito económico, abarca un segmento de actividad que se fundamenta en viajes motivados por la apreciación del sabor y aroma de los vinos y de las tradiciones de las localidades que lo producen (Dordio, 2011: 315) y que, frecuentemente, puede complementar el turismo rural u otras ofertas turísticas (Millán, 2012: 103).

En Castilla-La Mancha, dentro de un contexto de mejora de la calidad en los productos agroalimentarios tradicionales (vino, queso, aceite, berenjena, ajo morado,...), "los vinos han mejorado mucho durante las últimas décadas, pues parten de una difícil competencia con el de otras regiones más clásicas y tradicionales en el tratamiento del producto. Ofrecen una buena relación calidad-precio, siendo los vinos jóvenes y de crianza los más recomendables. A las variedades tradicionales, tanto en blanco (Airén) como en tinto (Cencibel), se le han unido para este último otras cepas foráneas (Cabernet Sauvignon, 
Merlot, Syrah) plantadas en espaldera y con riego por goteo" (Pillet, 2011: 732-733). Todo ello, sin duda, ha favorecido que muchas comarcas pudieran aprovechar su "potencial enogastronómico" (Pillet, 2015a: 9), junto con otros recursos patrimoniales.

Han surgido diferentes iniciativas que se encuentran en proceso de consolidación unas y con dificultades otras (Cuadro 2), debido a los problemas surgidos en estos últimos años como consecuencia de la crisis. En este nuevo escenario se han limitado las capacidades de inversión y de financiación, y las administraciones regionales y locales han visto reducidas sus posibilidades de ayuda a las redes de cooperación en torno a la cultura del vino, que se centraban básicamente en rutas e itinerarios promocionados desde el ámbito privado y público. El vino y el enoturismo han sido aprovechados también como nexos de unión de partenariados locales y comarcales, en los que se ha producido un aprendizaje colectivo sobre las oportunidades y limitaciones que tiene el territorio para su desarrollo y articulación, surgiendo iniciativas que pueden ser buenos modelos a seguir.

Especialmente destacables son las iniciativas público/privadas aunque puntualmente se encuentran inactivas dos de las que ofrecen un mayor interés. En primer lugar, la Ruta certificada Caminos del Vino de La Mancha, que se enmarcaba dentro de las Rutas del Vino promovidas por ACEVIN (Asociación Española de Ciudades del Vino), cuya presidencia ostenta el municipio de Alcázar de San Juan, agrupando siete municipios de la comarca de La Mancha (Alcázar de San Juan, Campo de Criptana, Pedro Muñoz, San Clemente, Socuéllamos, Tomelloso y Villarrobledo), hoy en proceso de reactivación. En segundo lugar, el Club Divinum Vitae, organismo privado que ofertaba actividades en 31 bodegas inscritas en el mismo e integradas en la Asociación de Turismo Enológico de Castilla-La Mancha. Por su parte, numerosas bodegas ofertan visitas de manera particular.

Además del caso de Alcázar de San Juan que estudiaremos más detalladamente en las páginas siguientes, otro caso representativo es el de Valdepeñas, donde se ubica el Museo del Vino y que se promociona, actualmente, desde el gobierno regional a través de la Ruta del Vino de Valdepeñas en la que se pueden visitar algunas de las bodegas más representativas de esta zona. Las mismas ofrecen hasta el momento información suficiente en Internet para poder realizar actividades de enoturismo en ellas y en los establecimientos adheridos, pero en base a algunas entrevistas con personas relacionadas con estas redes, no existe un plan de trabajo que mejore, amplíe o potencie la capacidad de atracción turística. Relacionado con la diversificación económica, las iniciativas públicas que abogan por la rehabilitación y posterior reorientación de espacios singulares vinculados con el vino ocupan un papel significativo. La más emblemática ha sido la rehabilitación de la antigua Bodega de los Llanos, cuya inauguración tuvo lugar el 4 de noviembre de 2014. Se trata de una bodega construida en 1875 por Don Miguel Caravantes que representa una de las primeras iniciativas vinculadas con la obtención de vinos de calidad a partir de la introducción de barricas de madera, hecho insólito en La Mancha de finales del siglo XIX. El edificio actual dispone de diversos espacios polivalentes: servicios de cafetería, de tapería, de tiendas gourmet y de productos de la tierra, un restaurante y dos salas de eventos. En la transmisión y promoción de todo este conjunto de elementos patrimoniales, las distintas asociaciones y colectivos de la sociedad valdepeñera como el Grupo Literario y Artístico El Trascacho, o Desde el Empotro Grupo A7, juegan un importante papel organizando certámenes de poesía, encuentros y tertulias literarias. 


\section{Cuadro 2}

\section{PRINCIPALES INICIATIVAS DE ENOTURISMO EN CASTILLA-LA MANCHA (2015)}

\begin{tabular}{|c|c|c|}
\hline TIPOS & INICIATIVAS & OBSERVACIONES \\
\hline $\begin{array}{l}\text { Iniciativas } \\
\text { público/ } \\
\text { privadas }\end{array}$ & $\begin{array}{l}\text { Ruta del Vino de Valdepeñas } \\
\text { Divinum Vitae. Asociación } \\
\text { de Turismo Enológico de } \\
\text { Castilla-La Mancha } \\
\text { Bodegas particulares }\end{array}$ & $\begin{array}{l}\text { Ruta Certificada. ACEVIN y Secretaría de Estado de Turismo. (Alcázar } \\
\text { de San Juan, Campo de Criptana, Pedro Muñoz, San Clemente, } \\
\text { Socuéllamos, Tomelloso y Villarrobledo). Inactiva actualmente. } \\
\text { Junta de Comunidades de Castilla-La Mancha (Valdepeñas, San } \\
\text { Carlos del Valle, Montiel, Torre de Juan Abad, Granátula de Calatrava, } \\
\text { Alhambra). Bodegas Real y la Bodega de las Estrellas. } \\
\text {---- } \\
\text { Asociación formada por } 31 \text { bodegas que se incluyen en } 10 \text { Rutas. } \\
\text { Colaboraba con la Dirección General de Turismo de Castilla-La Mancha. } \\
\text { Inactiva actualmente. } \\
\text {---- } \\
47 \text { Bodegas ofertan actividades. Portal de Turismo de Castilla-La Mancha }\end{array}$ \\
\hline Turoperadores & Rutas del Vino Vintage Spain & Organización y diseño de paquetes enoturísticos con visita a bodegas \\
\hline Ayuntamientos & $\begin{array}{l}\text { Campo de Criptana. "Tierra } \\
\text { de Gigantes" } \\
\text { Valdepeñas } \\
\text { Alcázar de San Juan }\end{array}$ & $\begin{array}{l}\text { Actividades de formación, gastronómicas, etc., coincidiendo con el Día } \\
\text { Europeo del Enoturismo } \\
\text {--- } \\
\text { Diversas actividades de enoturismo (Guías, visita a bodegas, etc.). } \\
\text { Asociacionismo. Fiestas de la Poesía y de la Vendimia. Día Internacional } \\
\text { del Enoturismo } \\
\text {--- } \\
\text { Concurso Regional de vinos "Tierra del Quijote", Noche del Vino y otras } \\
\text { actividades }\end{array}$ \\
\hline Museos & $\begin{array}{l}\text { Centro de interpretación } \\
\text { de la Alfarería Tinajera } \\
\text { (Villarrobledo) } \\
\text { Museo del vino (Valdepeñas) } \\
\text { Museo del carro y aperos de } \\
\text { labranza (Tomelloso) }\end{array}$ & $\begin{array}{l}\text { Elaboración de tinaja e instrumentos asociados } \\
\text {---- } \\
\text { Antigua bodega de Leocadio Morales (1901) rehabilitada donde se } \\
\text { celebran eventos relacionados con la cultura del vino. } \\
\text {--- } \\
\text { Tipos de carros y carruajes. Reconstrucción de un bombo, elemento } \\
\text { arquitectónico de gran interés. } \\
\text {---- } \\
\text { Mirador actualmente cerrado. Iniciativa no exenta de polémica (costes de } \\
\text { construcción, homologación anti-incendios). }\end{array}$ \\
\hline Ferias & $\begin{array}{l}\text { FENAVIN } \\
\text { (Ciudad Real) } \\
\text { FITUR } \\
\text { (Madrid) } \\
\text { Feria de los Sabores de } \\
\text { la Tierra de Don Quijote } \\
\text { (Alcázar de San Juan) }\end{array}$ & $\begin{array}{l}\text { Feria Nacional del Vino (Diputación Provincial de Ciudad Real) de } \\
\text { carácter comercial aunque alberga actos dedicados a la cultura del vino. } \\
\text { Feria Internacional de Turismo. Promoción de Rutas y otras actividades } \\
\text {---- } \\
\text { Carácter gastronómico y enoturístico. }\end{array}$ \\
\hline Otros & $\begin{array}{l}\text { Fundación "Tierra de } \\
\text { Viñedos" }\end{array}$ & $\begin{array}{l}\text { Vocación comercial de los vinos regionales y defensa del patrimonio } \\
\text { vitivinícola y de sus valores culturales y medioambientales }\end{array}$ \\
\hline
\end{tabular}

Fuente: elaboración propia. 
En definitiva, y según el último informe del Instituto de Promoción Turística, el enoturismo muestra unas óptimas capacidades de desarrollo para los próximos años, convirtiéndose, junto al gastronómico, en el complemento perfecto de un programa más amplio de turismo de calidad, es este caso enogastronómico, pues como ocurre en otras regiones, pueden ser, junto con la cultura, la atracción principal para visitar una región y no necesariamente una segunda (o complementaria) atracción del viaje (Rodríguez et al., 2010: 218; López-Guzmán et al., 2014: 172). Son, todos ellos de proyectos temáticos y territoriales que han tenido como protagonistas especiales a las administraciones autonómicas y locales, interesadas en una revitalización del territorio a partir del aprovechamiento de estos recursos específicos y de la dinamización de los colectivos más implicados: los productores de vino y las empresas turísticas.

\section{INNOVACIÓN Y TURISMO EN CASTILLA-LA MANCHA: EL CASO DE ALCÁZAR DE SAN JUAN}

Alcázar de San Juan es un municipio situado en la zona central de la región, en la comarca de La Mancha, con 31.269 habitantes (2015), que ha emprendido algunas acciones significativas de desarrollo local vinculadas con su tradición vitivinícola, dentro de un proyecto de ciudad con un fuerte liderazgo político-institucional que abarca las múltiples realidades de un núcleo urbano intermedio: la promoción económica, el bienestar social, la atención al medio ambiente, la innovación y el aprendizaje, y la participación ciudadana. Su trayectoria ha sido valorada en numerosos estudios sobre innovación y desarrollo territorial, liderazgo y formación de redes institucionales (Pardo, 1999; Méndez et al., 2006; Plaza, 2007; Prada, 2008; Méndez et al., 2009; Méndez, 2010; Michelini, 2010; Méndez y Prada, 2010; Plaza, 2011).

\subsection{La trayectoria de Alcázar de San Juan}

La vinculación de Alcázar de San Juan con la cultura del vino se remonta a los tiempos de su fundación como Villa en el siglo XIII, pero es a mediados del siglo XIX cuando la ciudad alcanza su mayor impulso al constituirse en el centro exportador de los vinos de La Mancha a través del ferrocarril Madrid-Alicante, que se convierte también en el motor de su industrialización (Gallego, 2009). Esta tradición agroindustrial se fue perdiendo a lo largo de la segunda mitad del siglo XX, a medida que se desarrollaba la red de transporte por carretera y el transporte del vino pasó a hacerse en camión desde las poblaciones de origen. Las mayores bodegas y alcoholeras próximas a la estación de ferrocarril fueron reconvirtiéndose en espacios residenciales, aunque la trama urbana quedó marcada por estos amplios espacios industriales. Al mismo tiempo, la ciudad se fue dotando de numerosos equipamientos (cárcel, juzgados, cuarteles, ambulatorio, institutos de enseñanzas medias, etc.) y de una gran influencia comarcal y territorial, aunque las dos últimas décadas del siglo XX fueran especialmente críticas por el desmantelamiento de la actividad ferroviaria y el inicio de procesos de deslocalización productiva en el marco de la nueva economía flexible. Su economía agraria y el abastecimiento de agua también resultaron afectados en estos años por la sobreexplotación de los acuíferos de la cuenca alta del Guadiana, que contribuyeron significativamente a la degradación y pérdida de biodiversidad de dos importantes espacios 
naturales protegidos: el Parque Nacional de Las Tablas de Daimiel y el Parque Natural de Las Lagunas de Ruidera, incluidos en la Reserva de la Biosfera de La Mancha Húmeda, declarada por la UNESCO en 1981. Por tanto, a finales del siglo XX, coincidieron tres procesos asociados con la globalización: crisis económica, crisis social y crisis ambiental, que obligaban a una revisión de la evolución seguida por la ciudad.

Siguiendo a Pardo (1999) y a Michelini (2010: 193), es a finales de los años ochenta cuando Alcázar de San Juan inició una importante transición socioeconómica liderada por los gobiernos locales, consistente en dos tipos de actuaciones. Por una parte, se defendió la idea de construir el Hospital General Mancha Centro, cuya obra culminó entre 1994 y 1995 y se amplió en 2008. Con este equipamiento se compensó el impacto provocado en la economía local por el desmantelamiento del sector ferroviario, y se recuperó su función urbana como centro de servicios, ahora para un área de influencia socio-sanitaria de más de 250.000 habitantes.

Por otro lado, se inició un amplio programa de desarrollo local para combatir el desempleo y apoyar y diversificar la actividad productiva, haciendo uso de instrumentos europeos, nacionales y regionales centrados en la formación de los trabajadores y la dinamización de yacimientos de empleo. Las primeras acciones de desarrollo local se enmarcaron dentro del Programa de Escuelas Taller y Casas de Oficios, y se continuaron después con la creación de una estructura técnica denominada Fundación para la Promoción Económica y el Empleo (FMPEE) en 1992. Durante los años siguientes, la FMPEE se fue dotando de distintas secciones de trabajo, como un Centro Local de Innovación y Promoción Económica (CLIPE), un Centro de Empresas y un Centro de Formación, que desarrollaron un importante know how para la diversificación económica, a través de la investigación e innovación sobre los recursos específicos de la ciudad y del territorio y el desarrollo de redes verticales y horizontales de cooperación, junto con coaliciones entre actores territoriales públicos y privados como Al-Centro orientada al refuerzo de la actividad comercial, Alces, dirigida a la gestión del suelo y la actividad industrial, y el Centro de Iniciativas Turísticas encaminado a la dinamización del turismo local.

Además de la política socio-sanitaria y de desarrollo local, la ciudad aprovechó otras oportunidades económicas, como la construcción de cuatro plantas de energía termosolar (Plaza, 2011), y un amplio programa de reformas urbanísticas y actividades culturales que elevaron la calidad de vida para hacer más atractivo el asentamiento de profesionales y especialistas, que en otras condiciones no hubieran decidido fijar su residencia familiar en Alcázar de San Juan.

\subsection{El desarrollo de la actividad turística como destino de interior a partir del patri- monio y de la cultura del vino}

La estrategia turística a partir del patrimonio y la cultura del vino en Alcázar de San Juan surgió con los primeros impulsos en materia de desarrollo local durante la legislatura 1987-1991, y se consolidó a partir de 2005 coincidiendo con el IV Centenario de la Publicación de la Primera Parte de Don Quijote La Mancha, evento en el que confluyen todos los recursos específicos de la localidad para configurar un producto turístico integrado. En esta trayectoria se pueden identificar varias fases: una primera de adquisición 
de competencias de los cuadros políticos y técnicos sobre estas cuestiones; una segunda de planificación y programación de actuaciones y organización de los distintos agentes, en la que se incluye la financiación del proyecto; una tercera fase de inversión pública para la rehabilitación de los recursos patrimoniales, y una cuarta de gestión y explotación del producto turístico con su revisión permanente para garantizar su atractivo y calidad. Todo este proyecto se organiza a dos niveles, uno local, dirigido por el Ayuntamiento y otro comarcal-regional, en coordinación con los municipios de la zona y el gobierno autonómico de Castilla-La Mancha. En definitiva, un plan de trabajo que ha mejorado, ampliado y potenciado las capacidades de la ciudad para convertirse en un destino de interior donde el vino y su patrimonio son parte esencial del territorio.

La fase de adquisición de competencias se fraguó mediante la colaboración del Ayuntamiento con otras ciudades en las que el vino formaba parte de su base económica, como Vilafranca del Penedés o Aranda de Duero, desembocando en la creación de la Asociación Española de Ciudades del Vino (ACEVIN). La participación en red de proyectos como VINADAPT (reciclaje y adaptación de trabajadores en activo) facilitó los primeros intercambios de conocimiento y la creación de una red de actores territoriales con intereses comunes sobre la economía del vino y la promoción del desarrollo local. Desde 1996, Alcázar de San Juan ha mantenido la presidencia de esta asociación de municipios y ha participado intensamente también en la Red Europea de Ciudades del Vino (RECEVIN).

Como ya se ha adelantado, el Ayuntamiento de Alcázar de San Juan participó durante la legislatura 1999-2003, junto a los municipios de Pedro Muñoz, Socuéllamos, Tomelloso, Valdepeñas y Villarrobledo, en el Proyecto Rutas del Vino de La Mancha, dentro de la iniciativa Caminos del Vino, promovido por ACEVIN y la Secretaría de Estado de Turismo y Turespaña, más tarde denominado Caminos del Vino de La Mancha. Este proyecto incluía la creación de un Centro de Iniciativas Turísticas, formándose así un partenariado de agentes públicos y privados con el vino como nexo de unión, que participó intensamente en actividades de articulación y capacitación de la oferta enoturística en cada municipio, y en distintas ferias como FITUR. A nivel local, la actividad del consistorio también fue incesante sobre otros activos culturales que reforzaban el proyecto turístico, como lo prueban los trabajos de valorización sobre las Órdenes Militares que repoblaron La Mancha durante la Edad Media, con sendos congresos internacionales sobre la Orden de San Juan en 2000 y 2002; y sobre los molinos de viento con la celebración de un congreso sobre Molinología en 2001, que daría lugar al Proyecto de Recuperación de la Zona Molinera de Alcázar de San Juan, y al diseño de un amplio conjunto de actividades que se organizarían y celebrarían con posterioridad.

Entre 2003 y 2007, la Concejalía de Turismo y Cultura programó distintos planes relacionados con el IV Centenario de El Quijote que se celebrarían a partir de 2005 mediante una amplia coordinación de todo el gobierno local: "La Locura del Quijote" que abarcaba toda la agenda cultural, social, educativa y deportiva de la ciudad, y "Alcázar, pretérito perfecto" orientado a la recuperación del patrimonio arquitectónico. Esta visión integrada ${ }^{2}$ planteaba la creación de un Centro de Recepción de Turistas aprovechando el edificio de la Capilla de Palacio (s. XVI), anexa al Conjunto Palacial del Gran Prior (s. XIII) donde será posible visitar un yacimiento arqueológico romano, la Iglesia de Santa María y el

2 http://www.turismoalcazar.es/index.php 
Torreón de Don Juan de Austria, con un Centro de Interpretación o Espacio Museográfico dedicado a los Caballeros Hospitalarios de la Orden de San Juan. A partir de este conjunto, el turista podría optar por tres itinerarios urbanos que articulan los espacios y edificios más significativos de la ciudad: el cervantino, con una primera visita al Museo de la Alfarería Manchega FORMMA, situado en el antiguo Convento de San José (s. XVII), el Museo Municipal (s. XVII), y la Casa del Hidalgo (s. XVI) que hoy alberga el Centro de Interpretación sobre el Hidalgo, e incluye una pequeña bodega donde se celebran catas de vino. Esta Casa del Hidalgo se comenzó a rehabilitar mediante una amplia escuela taller entre 2005 y 2007 que comprendía todos los oficios relativos a la rehabilitación de edificios antiguos. En ese mismo itinerario se puede visitar la Iglesia de San Francisco (s. XV) y el Hotel Santa Clara situado en el antiguo convento del mismo nombre levantado en el s. XVI. Ya en la periferia de la ciudad el itinerario cervantino conduciría al cerro molinero de San Antón, donde se sitúan cuatro molinos de viento, en uno de los cuales se instaló maquinaria para la molienda de la harina y en otro un Centro de Interpretación del Paisaje Manchego, desde el que se dominan las tierras y los colores propios del paisaje del viñedo manchego (Figura 4).

\section{Figura 4 \\ PAISAJE MANCHEGO DESDE LA SIERRA DE LOS MOLINOS DE ALCÁZAR DE SAN JUAN (CIUDAD REAL, CASTILLA-LA MANCHA)}

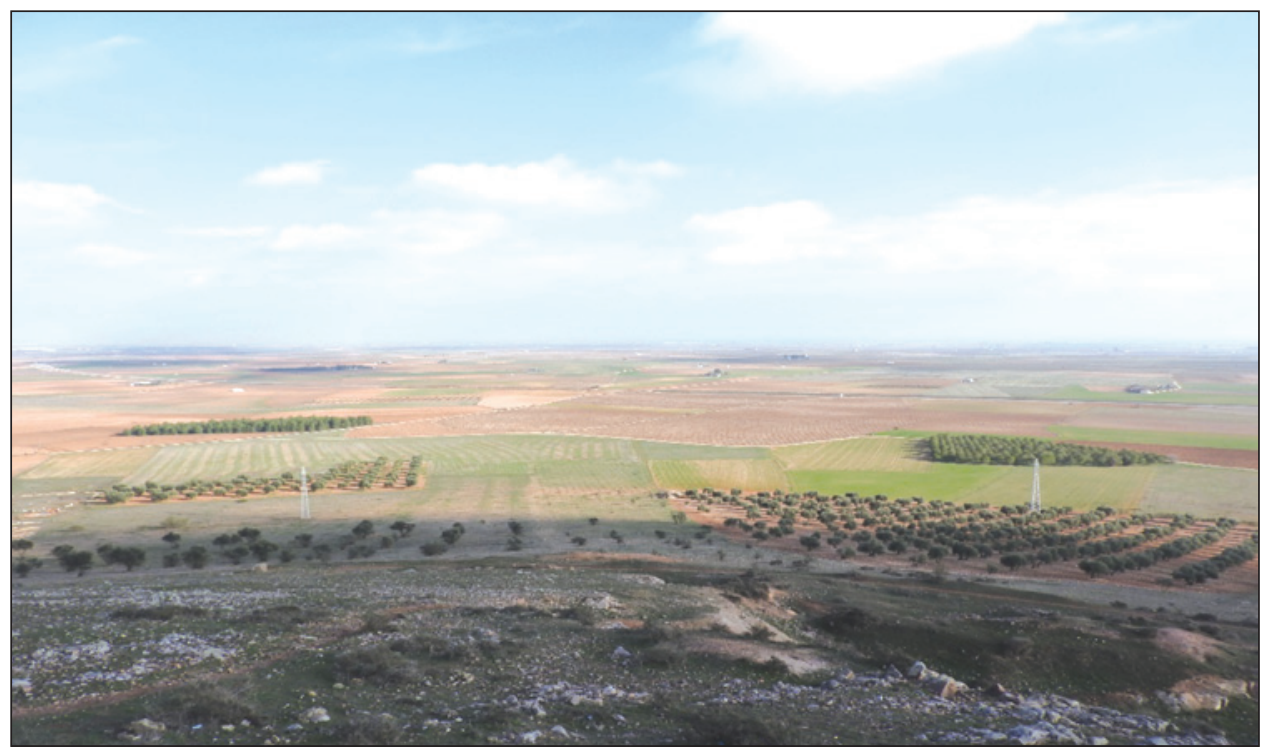

Fuente: Julio Plaza (2016).

Un segundo itinerario de carácter comercial conecta el centro histórico con la Plaza de España y la Estación de Ferrocarril a través del eje principal de la ciudad que es la calle Castelar, donde existe una abundante oferta gastronómica y de degustación de vinos en 
bares, restaurantes, y bodegas acondicionadas que ofrecen recursos enoturísticos, como la Bodega de La Tercia, cuyos titulares también forman parte del partenariado de empresarios locales interesados en la promoción turística de la ciudad. Finalmente, el tercer itinerario urbano conduciría a la visita de los edificios modernistas de la ciudad y las iglesias de Santa Quiteria (s. XVIII) y de La Santísima Trinidad (s. XVII).

Además de la cultura cervantina, el vino se convirtió en uno de los elementos principales de la agenda de eventos de la ciudad. El Centro de Iniciativas Turísticas y el Ayuntamiento organizaron en 2005 la Feria de Los Sabores de la Tierra del Quijote, con una amplia muestra de vinos manchegos, que después se ha venido celebrando anualmente hasta 2011 y luego cada dos años (en 2013 y 2015). Por su parte, la Asociación Rutas del Vino de La Mancha continuó su proceso de acreditación de la calidad para mantener la marca territorial, y de inversiones en mejoras urbanas y patrimoniales para elevar la oferta, gracias a la concesión de un Plan de Dinamización Turística por parte de la Junta de Comunidades de Castilla-La Mancha denominado "Rutas del Vino y Sabores de La Mancha”. La gestión pública se vio reforzada con la apertura de distintos alojamientos hasta alcanzar las 500 plazas hoteleras, el 40\% de ellas de tres y cuatro estrellas (Plaza, 2007).

El período siguiente (legislatura 2007-2011) estuvo protagonizado por el impacto de la crisis inmobiliaria y el aumento del desempleo vinculado a la construcción en sus primeros momentos, lo que obligó al Ayuntamiento a un esfuerzo especial para dinamizar la economía local a través de la obra pública y reforzar la diversificación económica. En los primeros meses de gobierno, el consistorio recibió una financiación especial del gobierno central a través del Fondo para la Modernización de Infraestructuras Turísticas (FOMIT) para la consolidación de su producto turístico de interior, que permitió avanzar en los proyectos de rehabilitación arquitectónica citados anteriormente, y su apertura en esos años. Con objeto de garantizar la calidad de la oferta turística, la Concejalía de Cultura y Turismo inició un Plan Estratégico de Turismo para revisar la situación del sector y la oferta de la ciudad, existiendo en 2010 un total de 44 empresas acreditadas con el sello Calidad de Destino Turístico (Villarejo, 2010: 22).

En relación con el vino, el acontecimiento más significativo fue la celebración del Concurso de Cata Regional de Vinos de la Tierra de Don Quijote en febrero de 2010, que se ha convertido en un evento anual de la agenda turística de Alcázar de San Juan, para cubrir uno de los momentos más débiles en la ocupación hotelera y la actividad comercial de la ciudad. La singularidad de este concurso está en que el jurado está formado por mil personas no expertas, si bien en la edición de 2011 se contó con la colaboración de la Asociación de Enólogos de Castilla-La Mancha, que incorporó al concurso un equipo de expertos que asesoró y dirigió la cata de los asistentes organizados en grupos. El concurso sigue el modelo del Concurso Nacional de Vinos celebrado en la ciudad de Mâcon (Francia), con la que Alcázar de San Juan está hermanada y mantiene una amplia colaboración institucional.

\subsection{La consolidación de la oferta turística y el relativo éxito del enoturismo}

A partir de 2011 y debido a los problemas de financiación de las administraciones públicas y a la caída del consumo privado, podemos apreciar un cierto contraste con el modelo de turismo de interior promovido en Alcázar de San Juan anteriormente. El nuevo gobierno 
local decidió mantener la agenda cultural y turística de la ciudad con ligeras variaciones y novedades de alcance local como la Noche del Vino y la celebración del Día Europeo del Enoturismo, y dedicó una atención especial a la promoción del enoturismo con la creación de la Concejalía de Desarrollo y Promoción Vitivinícola, más la existente de Turismo.

Sin embargo, esta dedicación no se ha visto correspondida por buenos resultados en la gestión del turismo local. Los datos estadísticos facilitados por la Oficina de Turismo de Alcázar de San Juan, relativos a pernoctaciones en hoteles entre 2010 y 2014, con resultados que van de 62.626 a 44.788 respectivamente, expresan el efecto negativo de crisis económica. Las visitas a los Museos y Centros de Interpretación se redujeron de 31.583 en 2010 a 30.661 en 2014, aunque tuvieron un espectacular incremento entre ambos años debido a las visitas de distintos colectivos como centros escolares y asociaciones de vecinos. El número de visitantes a la Oficina de Turismo evolucionó, sin embargo, positivamente entre 2010, con 2.603 consultas, y 2014, con 3.655 consultas, así como la atención a grupos organizados que pasó de 2.504 en 2010, a 3.755 en 2015 (Figura 5).

\section{Figura 5 \\ EVOLUCIÓN DE LOS INDICADORES DE ACTIVIDAD TURÍSTICA EN ALCÁZAR DE SAN JUAN (2010-2014)}

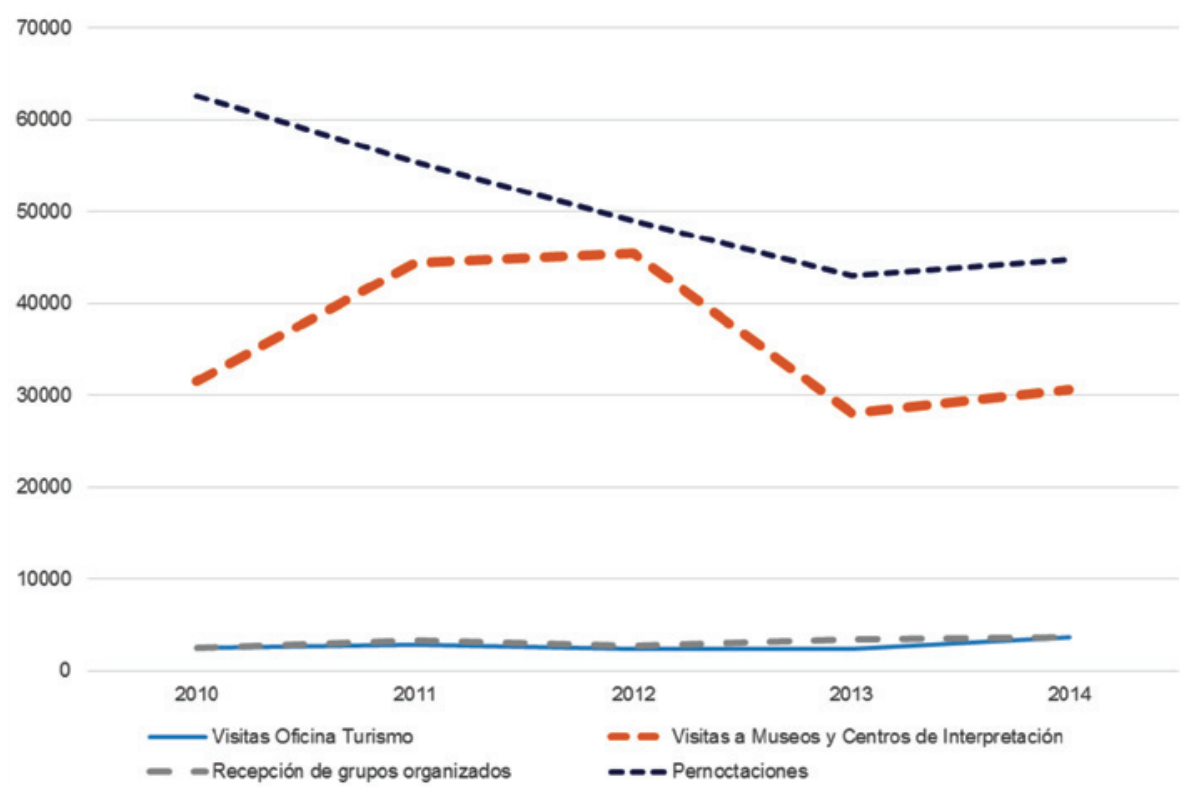

Fuente: Oficina de Información Turística de Alcázar de San Juan. Elaboración propia.

El origen de los turistas está siendo básicamente nacional: el 51,9\% de las consultas realizadas por turistas en la Oficina de Turismo fueron hechas por personas de Madrid $(25,9 \%)$, Comunidad Valenciana $(11,8 \%)$, Cataluña $(6,8 \%)$, y extranjeros $(6,8 \%)$ procedentes principalmente de Francia y Reino Unido. En relación con el motivo de la visita, un $37 \%$ de 
los turistas declara su interés por el turismo cultural y patrimonial, mientras sólo un 2,9\% se manifiesta interesado en la oferta enoturística, consistente en la visita a las bodegas que tienen actividades concertadas en la ciudad y en la comarca. Sin embargo, las estadísticas no recogen el carácter horizontal que ofrece la cultura del vino en el turismo de interior, presente en muchas manifestaciones de la vida cotidiana y del resto de ofertas turísticas. Así por ejemplo, un $12,4 \%$ de turistas que visitan la ciudad están interesados en la gastronomía y en los vinos, y el lugar más visitado por los turistas resulta ser el Cerro de San Antón y sus molinos de viento, desde donde se divisa el paisaje manchego por excelencia ocupado por viñedos. Del mismo modo, la celebración del Concurso Regional de Vinos y la Feria de Los Sabores garantizan el nivel de ocupación hotelera de la ciudad.

A nivel comarcal el proyecto Ruta del Vino de La Mancha (Caminos del Vino de La Mancha) ha perdido su reconocimiento de calidad dentro del programa Caminos del Vino de ACEVIN, de la que sigue ostentando la presidencia. La estructura en red para impulsar este proyecto, y el emprendimiento que acompaña, ha quedado enjuiciada por los problemas financieros de los municipios y el escaso interés de las grandes cooperativas que no ven beneficios inmediatos en la política enoturística. A pesar de ello, las empresas y bodegas de Alcázar de San Juan que están adheridas a esta iniciativa, continúan prestando servicios a demanda, y el Ayuntamiento tiene previsto, para los próximos años, promover un nuevo impulso en la organización de los agentes públicos y privados locales y comarcales, lo que exige nuevas investigaciones futuras que valoren la capacidad de resiliencia de estos modelos turísticos de interior y su gobernanza.

\section{CONCLUSIONES}

El medio rural se encuentra en una transición hacia modelos productivos más diversificados y diferenciados por su calidad y conexión con el territorio frente a los modelos productivistas, competitivos únicamente en precio del producto. Los cambios que exige la globalización para superar estos desafíos obligan a un aprovechamiento integral de los recursos específicos y a una mayor participación de los actores locales para promover nuevas formas de aprovechamiento y gobernanza. En la agricultura se han adoptado estrategias postproductivistas para una mejor integración en los mercados y una mayor diferenciación de los productos a partir de sus especificidades geográficas, entre las que se incluye el patrimonio, como elemento fundamental de la identidad territorial y de los productos turísticos. Ha sido en las regiones vitivinícolas donde este discurso ha sido más evidente y ha dado como resultado un notable desarrollo del enoturismo.

Sin embargo, los cambios ligados al postproductivismo agrario y al enoturismo no dependen exclusivamente de los productores y empresas agrarias, sino de coaliciones público-privadas en las que las administraciones locales han aportado herramientas de innovación para conseguir que estos cambios territoriales tengan éxito. En el caso de Castilla-La Mancha, esta región se encuentra en una situación crónica de sobreproducción que hace completamente dependiente al producto de los precios en los mercados exteriores. Frente a una política que ha fomentado el monocultivo, la diversificación de las explotaciones agrarias y la valoración del patrimonio cultural y el paisaje para desarrollar una economía menos dependiente de las exportaciones de vino es muy incipiente, y su 
organización y promoción depende en gran medida de los actores públicos locales, ahora condicionados presupuestariamente por los efectos de la crisis y las políticas de recorte de gasto. En este contexto cabe preguntarnos aún, si es posible la promoción del turismo y la consecuente diversificación de rentas a partir de una cultura del vino que pueda superar o equilibrar en resultados de empleo y calidad de vida a la política de precios de la que depende un cultivo con sobreproducción crónica.

A pesar de que la posible respuesta a esta cuestión quede más a favor de la competitividad en precios que de la diferenciación del producto y su calidad, la cultura del vino ofrece un alto potencial de innovación para dinamizar las identidades territoriales y transformar el tejido socioeconómico, pero exige un plan de trabajo a medio plazo que mejore, amplíe y potencie las estrategias de desarrollo. El caso estudiado de Alcázar de San Juan demuestra estas capacidades para construir capitales sociales territoriales, teniendo el vino como nexo de unión entre administraciones públicas, actores privados, y público en general. Para ello es esencial el diseño de un nuevo modelo de gobernanza, especialmente ante las dificultades financieras actuales, convencidos de que el éxito del turismo cultural y patrimonial, asociado a actividades de ocio y enogastronómicas, permite augurar cierto futuro, para una parte de los elaboradores de vino en la región.

La recuperación y valorización del conjunto de recursos específicos de carácter territorial es esencial para alcanzar un buen producto turístico, en este caso específicamente "enoturístico". El patrimonio agrario asociado aquí al cultivo del viñedo será el que contribuya a la identificación cultural de los vinos con sus paisajes y sus bienes patrimoniales tanto materiales como inmateriales, pero son los actores locales a través de su aprendizaje y organización, los que deben ser capaces de articular estrategias de desarrollo territorial que materialicen el escenario que perseguimos.

\section{BIBLIOGRAFÍA}

ALONSO, L.E. y CONDE, F. (1996): «Las paradojas de la globalización: la crisis del estado de bienestar nacional y las regiones vulnerables», Revista de Estudios Regionales, $\mathrm{n}^{\circ} 44$, pp. 87-124.

ARAGÓN, J.R.; PLAZA, J.J. y SERRANO DE LA CRUZ, M.A. (2015): «El camino hacia la consolidación de la Reserva de la Biosfera de La Mancha Húmeda para la valoración y ordenación definitiva del Alto Guadiana», en I Congreso Nacional Ciudad Real y su provincia. Ciudad Real, Instituto de Estudios Manchegos, pp. 489-504.

ARMESTO, X. (2005): «Notas teóricas en torno al productivismo agrario», Investigaciones Geográficas, n 36, pp. 137-156.

BERGSTROM, J.C. (2001): «Postproductivism and Rural Land Values». Department of Agricultural and Applied Economics, Faculty Series $n^{\circ} 01-20$, pp. 2-25.

CAÑIZARES, M.C. (2005): Territorio y Patrimonio Minero-Industrial en Castilla-La Mancha. Cuenca, Ediciones de la Universidad de Castilla-La Mancha.

CAÑIZARES, M.C. y RUIZ PULPÓN, A.R. (2014a): «Evolución del paisaje del viñedo en Castilla-La Mancha y revalorización del patrimonio agrario en el contexto de la modernización», en Scripta Nova, vol. XVIII, n498, 20 de diciembre de 2014. Universidad de Barcelona. Disponible en http:/www.ub.es/geocrit/sn/sn-498.htm. 
CAÑIZARES, M.C. y RUIZ PULPÓN, A.R. (2014b): «El viñedo en Castilla-La Mancha: el reconocimiento de un paisaje cultural», en Revalorizando el espacio rural: leer el pasado para ganar el futuro. Girona, Documenta Universitaria, pp. 305-316.

CAÑIZARES, M.C. y RUIZ PULPÓN, A.R. (2016): «Bases para la declaración como Bien de Interés Cultural del Paisaje del vino y el viñedo de la D.O. Valdepeñas (Castilla-La Mancha)», en Treinta años de Política Agraria Común en España. Ciudad Real, Grupo de Geografía Rural de la AGE, pp. 551-566.

CASTILlo, J. (2013) (Dir.): Carta de Baeza sobre el Patrimonio Agrario. Sevilla, Universidad Internacional de Andalucía. Disponible en http://www.patrimonioagrario.es/ pago/CARTA_DE_BAEZA_files/carta.pdf

DORDIO, V. (2011): «Os vinos de Múrcia: contributo de José Luís Andrés Sarasa», Cuadernos de Turismo, $\mathrm{n}^{\mathrm{0}} 27$, pp. 305-320.

EVANS, N. et al. (2002): «Conceptualising agriculture: a critique of post-productivism as the new orthodoxy», Progress in Human Geography, n 26, pp. 313-332.

GALLEGO, J.A. (2009): Ferrocarril y transición al capitalismo en La Mancha. 18501936. I. Reíles, granos y vinos. II. El campo tranquilo. Ciudad Real, Editorial Añil.

GETZ, D. y BROWN. G. (2006): «Critical sucess factors for wine tourism regions: a demand analysis», Tourism Management, vol. 27 (1), pp. 146-158.

ICOMOS (1999): Carta Internacional del Turismo Cultural. Disponible en http://www. international.icomos.org/charters/tourism_sp.pdf.

ILBERY, B. W. y BOWLER, I. R. (1998): «From agricultural productivism to postproductivism», en The Geography of rural change. London, Prentice Hall, pp. 57-84.

INE (2014): Contabilidad Regional de España, $1^{\text {a }}$ Estimación. Disponible en http://www. ine.es/prensa/np835.pdf

LÓPEZ TRIGAL, L. (2015) (Dir.): Diccionario de Geografía Aplicada y Profesional. León, Universidad de León.

LÓPEZ-GUZMÁN, T.; RODRÍGUEZ, J. y VIEIRA, A. (2013): «Revisión de la literatura científica sobre el enoturismo en España», Cuadernos de Turismo, n 32, pp. 171-188.

MARTÍNEZ, A. (2014): «La ruta del vino en la provincia de Alicante ¿oportunidad u oportunismo? », en Turismo y territorio: Innovación, renovación y desafíos. Valencia, Tirant Humanidades, pp. 503-513.

MATA, R. (2008): «El paisaje, patrimonio y recurso para el desarrollo territorial sostenible. Conocimiento y acción pública», Arbor. Ciencia, pensamiento y cultura, Vol. CLXXXIV, no 729 (enero-febrero), pp. 155-172.

MATHER, A.S. et al. (2006): «Post-productivism and rural land use: cul de sac or challenge for theorization? », Journal of Rural Studies, $n^{\circ} 22$, pp. 441-445.

MÉNDEZ, R. (2003): «Innovación y redes locales como estrategias de desarrollo territorial», Treballs de la Societat Catalana de Geografía, nº 55, pp. 177-198

MÉNDEZ, R. et al. (2006): «Ciudades intermedias y desarrollo territorial en Castilla-La Mancha», Xeográfica. Revista de Xeografía, territorio e medio ambiente, no 6, pp. 69-93.

MÉNDEZ, R. et al. (2009): «Desarrollo territorial, redes institucionales y procesos de innovación socioeconómica en Castilla-La Mancha», en Redes socioinstitucionales, estrategias de innovación y desarrollo territorial en España. Valencia, Universidad de Valencia, pp. 175-202. 
MÉNDEZ, R. (Ed.) (2010): Estrategias de innovación industrial y desarrollo económico en ciudades intermedias de España. Bilbao, Fundación BBVA.

MÉNDEZ, R., ABAD, L.D. y ECHÁVES, C. (2015): Atlas de la crisis. Impactos socioeconómicos y territorios vulnerables en España. Valencia, Tirant Humanidades.

MÉNDEZ, R.; MICHELINI, J.J. y ROMEIRO, P. (2006): «Redes socio-institucionales e innovación para el desarrollo de las ciudades intermedias», Ciudad y Territorio. Estudios Territoriales, $\mathrm{n}^{\circ}$ 148, pp. 377-396.

MÉNDEZ, R., y PRADA, J. (2010): «Ciudades y desarrollo territorial en Castilla-La Mancha», en Las escalas de la geografía: del mundo al lugar: homenaje al profesor Miguel Panadero Moya. Cuenca, Universidad de Castilla-La Mancha, pp. 152-174

MICHELINI, J.J. (2010): «Gobernanza territorial, iniciativas locales y desarrollo urbano: los casos de Getafe y Alcázar de San Juan», Boletín de la Asociación de Geógrafos Españoles, $\mathrm{n}^{\circ}$ 54, pp. 175-201.

MILLÁN, M. (2012): «Turismos de interior en la Región de Murcia. Una aproximación al turismo rural y al enoturismo», Polígonos, no 23 , pp. 87-112.

PARDO, I. (1999): Política Regional y Desarrollo Local. El caso de Alcázar de San Juan. Tesis Doctoral, Universidad de Castilla-La Mancha, 406 p. Disponible en https://ruidera.uclm.es/xmlui/handle/10578/1021

PEDRAJA, M. y MARZO, M. (2014): «Desarrollo del enoturismo desde la perspectiva de las bodegas familiares», Cuadernos de Turismo, no 34 , pp. 233-249.

PILLET, F. (2008): Espacio y ciencia del territorio: proceso y relación global-local. Madrid, Biblioteca Nueva.

PILLET, F. (2011): «El turismo de interior y el patrimonio territorial en Castilla-La Mancha», Cuadernos de Turismo, no 27, pp. 725-741.

PILLET, F. (2012): «El turismo de interior en la España peninsular: el patrimonio territorial como destino turístico», Boletín de la Asociación de Geógrafos Españoles, $\mathrm{n}^{\circ}$ 59, pp. 345-366.

PILLET, F. (2015a): «30 años de autonomía en Castilla-La Mancha: ¿ordenación territorial o pentaprovincia? », Investigaciones Geográficas, nº 63, pp. 5-15.

PILLET, F. (2015b): «Del espacio geográfico al turismo como uso y disfrute del territorio comarcal: una reflexión teórica desde España», Revista de Geografía Norte Grande, $\mathrm{n}^{\circ} 62$, pp. 185-201.

PILLET, F., CAÑIZARES, M.C., RUIZ, A.R., MARTÍNEZ, H.S., PLAZA, J. y SANTOS, J.F. (2014): «Applying the European Spatial Development perspective in low-density regions: a methodology based on mobility and labour market structure», Urban Studies, vol. 51 (3), pp. 577-595.

PLAZA, J.J. (2007): «Desarrollo Local. Gestión del Paisaje y del Patrimonio como estrategias para reducir la presión sobre las aguas subterráneas de La Mancha. El caso de Alcázar de San Juan», en V Congreso Internacional de Ordenación del Territorio. Málaga, FUNDICOT, pp. 1205-1209.

PLAZA, J.J. (2011): «El desarrollo de la energía termosolar en La Mancha: innovación territorial, diversificación económica, gestión del agua y sostenibilidad», en Energía y territorio. Dinámicas y procesos. XXII Congreso de Geógrafos Españoles. Murcia, Asociación de Geógrafos Españoles y Universidad de Alicante, pp. 387-398. 
PRADA, J. (2008): «Innovación y medio ambiente en ciudades medias: el caso de Alcázar de San Juan», en Ciudades, culturas y fronteras en un mundo en cambio: actas del IX Coloquio de Geografía Urbana. Sevilla, Asociación de Geógrafos Españoles, pp. 55-66.

RAMIREZ, S. y DEL CANTO, C. (2008): «Producciones agroalimentarias de calidad en el espacio rural madrileño», en Actas del XI Coloquio Ibérico de Geografía. Alcalá de Henares, s/p.

RODRÍGUEZ, J., LÓPEZ-GUZMÁN, T.; CAÑIZARES, S.M. y JIMÉNEZ, M. (2010): «Turismo del vino en el Marco de Jerez, Un análisis desde la perspectiva de la oferta», Cuadernos de Turismo, $\mathrm{n}^{\circ}$ 26, 217-234.

ROSENBERG, R.S. y WALSH, R.G. (1997): «Nonmarket Value of Western Valley Ranchland Using Contingent Valuation», Journal of Agricultural and Resource Economics, $\mathrm{n}^{\circ} 22(2)$, pp. 296-309.

RUIZ PULPÓN, A.R. (2012): «Gestión del agua e integración de políticas sectoriales. Balance y situación actual en el territorio del Alto Guadiana», Documents D'Anàlisi Geogràfica, vol 58 (1), pp. 101-120.

RUIZ PULPÓN, A.R. (2013): «Producción agroalimentaria de calidad y postproductivismo agrario: el caso de los vinos de pago en Castilla-La Mancha», Anales de Geografía de la Universidad Complutense, vol.33, $\mathrm{n}^{\circ} 2$, pp. 137-154.

RUIZ URRESTARAZU, E. (2001): «Patrimonio rural y políticas europeas», Lurralde Investigación y espacio, $\mathrm{n}^{\mathrm{O}}$ 24, pp. 305-314.

SEGRELLES, J.A. (2001): «Problemas ambientales, agricultura y globalización en América Latina», en Scripta Nova, vol.XVIII, n 92, 1 de julio de 2001, Universidad de Barcelona. Disponible en http://www.ub.edu/geocrit/sn-92.htm.

SHORT, B. (2006): «Idyllic ruralities», en Handbook of Rural Studies. London, SAGE Publications Ltd, pp. 133-149.

SILVA, R. (2009): «Agricultura, Paisaje y Patrimonio Territorial. Los paisajes de la agricultura vistos como patrimonio», Boletín de la Asociación de Geógrafos Españoles $\mathrm{n}^{\mathrm{o}} 4$, pp. 309-334.

TORRE, A. y WALLET, F. (2015): «Towards New Paths for Regional and Territorial Development in Rural Areas», European Planning Studies, vol. 23, n 4, pp. 650-677, VILLAREJO, D. (2010): «El Secretario de Estado de Turismo inaugura la Capilla de Palacio», Diario Lanza, 14 de julio de 2010, pp. 22.

WILSON, G.A. y BURTON, R.J.F. (2015): «Neo-productivist agriculture: spatio-temporal versus structuralist perspectives», Journal of Rural Studies, $\mathrm{n}^{\circ} 38$, pp. 52-64.

WOODS, M. (2005): Rural geography: Processes, responses and experiences in rural restructuring. London, SAGE Publications Ltd.

\section{RECURSOS WEB (Actualizados a 27 de septiembre de 2016):}

ACEVIN. Asociación Española de Ciudades del Vino. http://www.acevin.es/

Ayuntamiento de Alcázar de San Juan. http://www.alcazardesanjuan.es/ portal/home. jsp?codResi=1\&language=es

Ayuntamiento de Campo de Criptana. http://www.campodecriptana.es/

Ayuntamiento de Tomelloso. http://www.tomelloso.es/ 
Ayuntamiento de Valdepeñas. http://www.valdepenas.es/VLDSedeWeb/Modulos/VLDPortal.nsf

Ayuntamiento de Villarrobledo. http://www.villarrobledo.com/

Bodega de La Tercia (Alcázar de San Juan). http://www.bodegalatercia.com/es/principal.php Fundación "Tierra de Viñedos". http://www.tierradevinedos.org/index.php/es/

INE. Instituto Nacional de Estadística. http://www.ine.es/

Instituto Andaluz del Patrimonio Histórico. http://www.iaph.es/web/canales/patrimoniocultural/

RECEVIN. Red Europea de Ciudades del Vino. http://www.recevin.net/

Rutas del Vino de España. http://www.wineroutesofspain.com/

Ruta del Vino de Valdepeñas. Junta de Comunidades de Castilla-La Mancha. http:// www.turismocastillalamancha.es/rutas-en-castilla-la-mancha/ruta-del-vino-devaldepenas $/ ? \mathrm{t}=24$

Rutas del Vino Vintage Spain. http://www.enoturismoygastronomia.com/empresas/12rutas-de-vino-vintage-spain.html 
